\title{
3 Research Square \\ Biochemical influence of amphidromous shrimps on stream ecosystems in Japan
}

Hiromi Uno ( $\square$ hiromiuno1@gmail.com )

Center for Ecological Research, Kyoto University

Keitaro Fukushima

Center for Ecological Research, Kyoto University

Mariko Kawamura

Seto Marine Biological Station, Kyoto University

Akira Kurasawa

Center for Ecological Research, Kyoto University

Takuya Sato

Department of Biology, Kobe University

\section{Research Article}

Keywords: Excretion, nutrient, migration, benthic, water

Posted Date: April 8th, 2021

DOI: https://doi.org/10.21203/rs.3.rs-310474/v1

License: (c) (1) This work is licensed under a Creative Commons Attribution 4.0 International License. Read Full License 


\section{Abstract}

Not only through species interactions but also through excretion of nutrients, consumers can have profound effects on the ecosystem structure. While many studies in lentic ecosystems address both effects in combination, little is known about their linkages in lotic ecosystems. By a combination of field manipulative experiment, excretion measurements of consumes, and field surveys, we evaluated biochemical effects of amphidromous shrimps on stream ecosystems. The field manipulative experiment showed that the presence of shrimp suppressed the total aquatic insect biomass by $9 \%$ but increased the total benthic macroinvertebrate biomass including the shrimps by $196 \%$. The biomass-specific $\mathrm{NH}_{4}{ }^{+}$ excretion rate by shrimp was similar to aquatic insects, and the calculated mean $\mathrm{NH}_{4}{ }^{+}$excretion by benthic macroinvertebrate assemblage was $144 \%$ higher in the presence of shrimps. On the other hand, shrimps excreted much less $\mathrm{PO}_{4}{ }^{3-}$ than aquatic insects, and the $\mathrm{PO}_{4}{ }^{3-}$ excretion by the benthic macroinvertebrate assemblage did not change by the presence of shrimps. The field survey showed a positive correlation between $\mathrm{NO}_{3}{ }^{-}$concentration in stream water and shrimp density, suggesting that the excess $\mathrm{NH}_{4}{ }^{+}$was nitrified and raised $\mathrm{NO}_{3}{ }^{-}$concentration. In contrast, $\mathrm{PO}_{4}{ }^{3-}$ concentration in stream water was negatively associated with the shrimp density, indicating that the dominance of shrimps that excrete little $\mathrm{PO}_{4}{ }^{3-}$ decreased the $\mathrm{PO}_{4}{ }^{3-}$ concentration. While nutrient concentration of stream water is often attributed to the condition of the watershed area, the results of this study indicate downstream connectivity to the ocean can also influence the nutrient dynamics of the stream through the density of amphidromous shrimps.

\section{Introduction}

The number of animals can greatly vary by habitats or by years for various reasons such as habitat connectivity (Hanski \& Kuussaari 1995), diseases (Scheibling 1986), and natural catastrophes (GuhaSapir et. al. 2004). Many studies have shown that the density of animals can directly influence other organisms through species interactions such as direct consumption (Paine 1980; Carpenter 1985) and resource competition (Tilman 1977). Furthermore, studies in lentic ecosystems have shown that animals also influence nutrient cycling through their excretion of waste products (Kitchell et al. 1979; Vanni 2002). On the other hand, in lotic ecosystems, the chemical aspects of consumer effects have been understudied because the water flow makes the evaluation of the effects of animal excretion in lotic ecosystems challenging. Yet, some careful studies have shown that patchy distribution of fishes can create spatial heterogeneity in nutrient concentration in stream water (McIntyre et al. 2008), and the presence of a specific consumer species can alter nutrient cycling in streams (Hall et al. 2003). In reality, consumers influence the ecosystem structures both through species interactions and through nutrient addition by excretion, and the combined evaluations of the biochemical influence of consumers are needed to truly understand the influence of consumers on the stream ecosystems (Vanni \& Layne 1997).

In intact coastal streams, a large proportion of aquatic organisms exhibit migration between streams and the ocean or lakes (Myers 1949). For obligate migratory organisms, disruptions of the migration routes 
limit their distribution in streams. Therefore, large variation in consumer densities exists among streams depending on the hydrological connectivity of river networks. Many studies have shown that salmon-run from the ocean can have significant direct and indirect effects on stream ecosystems (Gende et al. 2002). Childress et al. (2015) have shown that migration of iteroparous fishes can also provide nutrients to stream ecosystems through nutrient inputs by excretion, decomposed unfertilized eggs etc, and increase the productivity in streams. While such anadromous fishes that come to streams for spawning transport nutrients from the ocean or lakes to streams (Material subsidy), many other migratory organisms that exhibit amphidromous or catadromous migration rather stay in streams for a prolonged period (McDowall, 1988) and should influence the local stream ecosystem as a newly added consumer species (Process subsidy) (Flecker et. al., 2010). Yet, studies evaluating the effect of process subsidies are limited compared to the material subsidies (Flecker et. al., 2010).

The presence of a migratory consumer as the process subsidy would not only influence the resident consumer species through species interactions but also influence the nutrient cycling through their excretion (Taylor et al. 2006; Flecker et. al., 2010). The addition of a migratory consumer would likely reduce the biomass of other resident consumers through species interactions. Yet, if the added species utilize resources more effectively than others do, the total biomass of consumers would be increased by the addition of the new species (Tilman 1977). Furthermore, mass-specific excretion rates vary by consumer species (McManamay et al. 2011), and change in dominant species would influence the nutrient cycling (Evans-White et al. 2005; Mclntyre et al. 2007). Therefore, to understand the chemical influences of a migratory consumer as the process subsidy, we need to know the biological impacts of the consumer species on the whole assemblage as well as the excretion rate by the composing species.

In many coastal streams in the mid-low latitude region, amphidromous shrimps often dominate the headwater streams (Covich 1988; Mantel \& Dudgeon 2004; Cross et al. 2008). Because of their migratory life cycles, where their larvae exhibit planktonic form in estuaries (McDowall, 1988), their densities can significantly vary among streams depending on the physical accessibility from the ocean (Greathouse et al. 2006). Benstead et al. (2010) have estimated the total nutrient excretion by amphidromous shrimps in tropical streams and concluded that shrimp excretion should play a significantly large role in nitrogen cycling in tropical streams. On the other hand, a number of studies have shown that the presence of amphidromous shrimps can suppress the aquatic insect biomass through direct consumption or resource competition (Pringle et al. 1993; Greathouse et al. 2006). While a significant amount of nutrient excretion by shrimps is added by their presence, the nutrient excretion by aquatic insects may be reduced by the reduction in their biomass. The effect of shrimps may also differ by nutrient elements because previous excretion studies have shown that crustaceans including shrimps excrete very little phosphorous compared to aquatic insects while their excretion rate of nitrogen is equivalent to aquatic insects (McManamay et al. 2011).

Here we aim to evaluate the biochemical influence of amphidromous shrimps on stream ecosystems. First, we conducted a field manipulative experiment to examine how the presence of shrimps influence benthic communities. Then to examine the change in nutrient cycling by the shrimps, we calculated 
nutrient output from the whole benthic macroinvertebrate assemblages in the presence/absence of shrimps by excretion measurement of major aquatic insect taxa and shrimp. Finally, we conducted a broad field survey of streams with various shrimp densities to examine how the difference in nutrient export from benthic macroinvertebrates induced by the shrimp densities influences the material cycling in streams. As a whole, we discern the biochemical influences of the amphidromous shrimps on stream ecosystems, by a combination of a field manipulative experiment, excretion measurement of consumers, and field surveys.

\section{Methods}

\section{Study system}

This study was conducted in the southern part of Wakayama Prefecture, Honshu, Japan (Fig. 1). Wakayama Prefecture is located in Kii Peninsula that faces the North Pacific Ocean. In this area, the climate on aquatic ecosystems is largely influenced by Kuroshio that is the warm current, and provides the habitats of tropical-subtropical diadromous organisms such as a giant mottled eel Anguilla marmorata and some species of atyid shrimps (Saito et al. 2012; Nagasawa et al. 2020). In these streams, various amphidromous fishes and invertebrates including shrimps inhabit where the migration route from the ocean is sustained (Tanaka et al. 2020), and benthic macroinvertebrate assemblages consist of diverse aquatic insects and amphidromous shrimps.

\section{Field manipulative experiment}

To investigate the biological effect of shrimps on the benthic communities directly, we carried out a field manipulative experiment in the Takase-river. By excluding shrimps from certain areas of the streams, we examined the change in the aquatic insect assemblages as well as their potential food resources to examine the processes of the species interactions between the shrimps and the aquatic insect assemblages. Within a $500 \mathrm{~m}$ segment of the river, we set four blocks in distinct pools, and within each block, we set four experimental cages. Each cage consists of $\sim 10 \mathrm{~L}$ of pebbles filled in a $30 \mathrm{~cm}$ by $50 \mathrm{~cm}$ $8 \mathrm{~cm}$ deep tray with $2 \mathrm{~cm}$ mesh, and an electric fence (Pringle \& Blake 1994; Moerke et al. 2017; Fig. S1), which selectively remove large animals including shrimps was placed on top. Over the experimental period, the electric fences of two cages were electrified, and the other two were not electrified. Three $3 \mathrm{~cm}$ by $3 \mathrm{~cm}$ tiles were tied on each cage to examine the chlorophyll-a and benthic fine particulate organic matter (BFPOM). Two binds of major riparian tree leaves, Mallotus japonicus and Quercus serrata, were tied to each cage to examine the decomposition rate of leaves during the experiment. The field manipulative experiment was initiated on March 17, 2020, and retrieved on April 21, 2020.

The number of shrimps on each cage was counted in daytime and nighttime in the first week of the experiment. At retrieval of the experiment, all aquatic insects in each cage were collected to estimate their densities. Aquatic insects were sorted at the family level, then the total dry weight of all aquatic insects in each chamber was measured finally. The tiles were collected, and loose organic materials on the tiles 
were flushed with water onto $70 \mu \mathrm{m}$ mesh as BFPOM, and their dry weight was measured at the lab. Periphyton on each tile was brush washed with $<100 \mathrm{ml}$ stream water and collected into a bottle, then filtered onto a GF/F filter (Whatman, Maidstone, UK). Chlorophyll-a was extracted with DMF (Dimethylformamide) and spectro-fluorometry (RF-5300PC, Shimadzu, Japan) was used to estimate the mean chlorophyll-a per area on each sampled area following the methods described by Suzuki and Ishimaru (1990). The bound leaves were dried and weighed after the experiment, and their decomposition rate was calculated.

\section{Measurement of consumer excretion}

To calculate the whole nutrient excretion by benthic macroinvertebrates in the presence/absence of shrimp, we measured the excretion rate of major aquatic insect taxa and shrimp following the methods used by Benstead et al. (2010) and McManamay et al. (2011). The excretion measurement was carried out at night time (20:00-25:00) on July 23,2020 , and daytime (8:00-12:00) on July 24, 2020, in Takaseriver. Five individuals of major shrimp and aquatic insect taxa were collected with a dip net respectively. Each individual was held less than 15 minutes before the start of the excretion experiment. Incubations were carried out by introducing each shrimp in $100 \mathrm{ml}$ and each insect in $30 \mathrm{ml}$ of stream water filtered with GF/F filter. As chironomid midges were small, five individuals were incubated together in $30 \mathrm{ml}$ of water. Each individual was incubated for 50 to 70 minutes, and we confirmed all individuals were behaving normally through the incubations. Then at the end of the experiment specimens were frozen in individual bottles, and each incubated water was filtered with a $0.45 \mu \mathrm{m}$ membrane filter (25CS045AN, Toyo Roshi Kaisha, Japan) and frozen until analysis. The dry weight of each specimen was measured. All the water samples were frozen in the field and transported to the lab facility at the Center for Ecological Research, Kyoto University. Inorganic nitrogen $\left(\mathrm{NO}_{3}{ }^{-}, \mathrm{NO}_{2}{ }^{-}\right.$, and $\left.\mathrm{NH}_{4}{ }^{+}\right)$and phosphorous $\left(\mathrm{PO}_{4}{ }^{3-}\right)$ concentrations in the water samples were measured colorimetrically using an autoanalyzer (QuAAtro 2$\mathrm{HR}, \mathrm{BLTEC}$, Japan). Because the $\mathrm{NO}_{2}{ }^{-}$concentration was immeasurably low, we show the sum of $\mathrm{NO}_{3}{ }^{-}$ and $\mathrm{NO}_{2}{ }^{-}$concentration as $\mathrm{NO}_{3}{ }^{-}$concentration in the present study.

\section{Field survey}

To examine if biochemical impacts of shrimps found in the field manipulative experiment and the measurement of consumer excretion can explain (extrapolate) the natural variation of water nutrient concentration among streams, we conducted a biochemical field survey at sites with a wide range of shrimp density. The field survey was conducted at 13 sites in four watersheds, the Tonda River, the Takase River, the Hiki River, and the Koza River (Fig. 1). The Tonda River and the Takase River meet at their river mouth and share the estuary. All sites were located in distinct tributaries of the rivers, and the watershed area of the study sites ranged from $0.8 \mathrm{~km}^{2}$ to $10.4 \mathrm{~km}^{2}$ (Table S1). Most of the watershed area was covered by natural broadleaf forest or artificial coniferous forest. The geology of the study watersheds is dominated by the Cenozoic accretionary complexes composed of sandstone, mudstone, and shale (Takao et al. 1981). No study sites had dams upstream, but five sites had large dams downstream (Tonoyama-dam 64-meter height, and Shichikawa-dam 59-meter height). All samplings were 
conducted in November 2017 within 5 days, and there was no precipitation during the sampling period. At each site, samplings were repeated twice in day time and night time on the same day because the shrimps were strictly nocturnal in the system. Daytime sampling was conducted between one hour after the sunrise and one hour before the sunset, and nighttime sampling was conducted between one hour after the sunset and one hour before the sunrise.

Shrimp density was estimated with $50 \mathrm{~cm} \times 50 \mathrm{~cm}$ quadrat for five times at random locations in each site at night. Aquatic insect assemblages were sampled with $30 \mathrm{~cm} \times 30 \mathrm{~cm}$ Surber-net sampler three times at randomly selected locations in each site and time (day time and night time) to estimate the density. Sampled aquatic insects were preserved in $99 \%$ ethanol on-site, and $>0.5 \mathrm{~mm}$ individuals were sorted to family level under compound microscope at lab. The total dry weight of all aquatic insects collected at each site was measured finally. Algae were sampled from three cobbles at each site: $36 \mathrm{~cm}^{2}$ of the cobble surface was scrubbed with a toothbrush to collect algae, then chlorophyll-a density was estimated as described above. $100 \mathrm{ml}$ water sample was collected at each site, filtered with GF/F within 24 hours. Then the filtered water samples were frozen until analysis. Inorganic nitrogen $\left(\mathrm{NO}_{3}{ }^{-}, \mathrm{NO}_{2}{ }^{-}\right.$, and $\left.\mathrm{NH}_{4}{ }^{+}\right)$and phosphorous $\left(\mathrm{PO}_{4}{ }^{3-}\right)$ concentrations in the water samples were analyzed as described above.

\section{Data analysis}

Field manipulative experiment-The field manipulative experiment enabled us to compare the effect of shrimps on major aquatic insect taxa and their potential food sources between shrimp and no shrimp treatments. We assessed the differences of their abundance between shrimp and no shrimp treatment using a one-way ANOVA including block as random factor by Linear Mixed Model using the Imer() function in Ime4 package and the anova() function in the ImerTest package in Program R. We logtransformed aquatic insect density to satisfy assumptions of normality prior to the analysis.

\section{Calculation of total excretion by benthic macroinvertebrates assemblages-}

Total nutrient excretion by benthic macroinvertebrates in the presence/absence of shrimps were calculated based on the results of the electroshock experiment and the excretion measurement of major aquatic insect taxa and shrimp. For each nutrient element, we multiplied the taxon-specific excretion rate by the density of each taxon in the presence/absence of the shrimps in the experiment and summed up the excretion rates by all taxa. For minor taxa ( $<5 \%$ in total) whose taxon-specific excretion rates were not measured, we applied the excretion rate of Diptera as they were mostly as small as Diptera. Similarly, we calculated the total dry weight of benthic macroinvertebrates in the presence/absence of the shrimps.

Field survey-We compared the effect of shrimps and several watershed characters on water chemistry and major aquatic insect density across surveyed sites. As watershed characters, we included elevation of the sampling site, drainage area, forest rate, natural forest rate, shrimp presence, and shrimp density measured at each site (Table S1). Watershed characters were estimated using the ArcGIS system, and 
forest rate and natural forest rate of each watershed were estimated based on the 1:25,000 vegetation map provided by the Biodiversity Center of Japan, Ministry of the environment, Japan (http://gis.biodic.go.jp/webgis/index.html). For the analysis, we defined the natural forest as the sum of primary and secondary broadleaf forest, and defined the forest as the sum of natural forest and the artificial plantation conifer forests. We first checked the collinearity among all variables included in each analysis using correlation coefficients and variance inflation factors (VIF). A VIF score greater than 4 and a correlation coefficient greater than 0.7 were used to eliminate habitat variables considered to have a high degree of collinearity (Zuur et al. 2010). There was a high degree of collinearity and VIF scores between the shrimp presence and the elevation and between the shrimp presence and shrimp density (Table S2). Therefore, we excluded the shrimp presence from the analyses. We log-transformed shrimp and aquatic insect density to satisfy assumptions of normality prior to all the analysis.

We generated a list of linear mixed-effects models with the stream as a random effect and all combinations of two or fewer predictor variables as fixed effects without interactions. We standardized the independent data to a mean of 0 and standard deviation of 2 so that effect sizes of independent variables could be compared. Models with $\triangle \mathrm{AICc}<4$ were retained to form candidate model sets and were averaged using the MuMIn package in $\mathrm{R}$ (Table S2). To evaluate the effect of shrimps and watershed character variables on water chemistry and aquatic insect density, we considered the magnitude and direction of the averaged coefficient, whether the $95 \%$ confidence intervals spanned zero, and the relative variable importance (RVI) of each variable. The latter is calculated as the sum of the model weights of all the models in the final confidence set in which the variable appears (Burnham and Anderson, 2002). All analyses were performed in the software R.

\section{Results}

\section{Field manipulative experiment}

Electro-fencing successfully excluded shrimps in the experimental cages, and no shrimps were observed in the treatment with electroshock ("no shrimp" treatment), while two shrimps Paratya compressa and Palaemon paucidens were respectively observed at $14.2 \pm 2.9$ and $0.8 \pm 0.8$ individuals $\mathrm{m}^{-2}$ in the treatment without electroshock ("with shrimp" treatment) (Fig. 2A). Chlorophyll-a was significantly higher with shrimp (Fig. 2B; see Table S3 for statistics), and the amount of BFPOM was significantly lower with shrimp (Fig. 2C). The decomposition rate was not significantly different by the presence of shrimps (Fig. 2D, 2E). Except the shrimps, Heptageniidae, Chironomidae, Baetidae, Leptophlebiidae, Athricidae, and Perlidae were the six most dominant taxa occupying $95 \%$ of all benthic macroinvertebrate assemblage in density (Fig. 2G-L). Among the six most abundant aquatic insects, Chironomidae was significantly reduced in the presence of shrimp (117 \pm 34 individuals $\mathrm{m}^{-2}$ compared to $358 \pm 108$ individuals $\mathrm{m}^{-2} ; F_{1,11}=6.4, P<0.05$ ), and Baetidae was significantly abundant in presence of shrimp (190 \pm 38 individuals $\mathrm{m}^{-2}$ compared to $98 \pm 22$ individuals $\left.\mathrm{m}^{-2} ; F_{1,11}=5.7, P<0.05\right)$. The density of Heptageniidae, Leptophlebiidae, Athricidae, and Perlidae were not significantly different by the 
presence/absence of shrimps. The total dry weight of aquatic insects was not significantly different in the presence/absence of shrimps (Fig. 2F).

\section{Measurement of consumer excretion}

$\mathrm{NH}_{4}{ }^{+}$and $\mathrm{PO}_{4}{ }^{3-}$ concentration significantly increased after the incubation of benthic macroinvertebrates, while the increase in the $\mathrm{NO}_{3}{ }^{-}$and $\mathrm{NO}_{2}{ }^{-}$concentration was immeasurable (Table $1 \mathrm{~A}$ ). $\mathrm{NH}_{4}{ }^{+}$excretion rate of major aquatic insects, Ephemeroptera (Heptageniidae), Diptera (Chironomidae), Plecoptera (Perlidae) and Odonata (Gomphidae) were $0.016 \pm 0.004,0.0035 \pm 0.0011,0.019 \pm 0.006$, and $0.044 \pm 0.009 \mu \mathrm{mol}$ $\mathrm{hr}^{-1}$ respectively. $\mathrm{NH}_{4}{ }^{+}$excretion rate by Paratya compressa shrimp was $0.96 \pm 0.12 \mu \mathrm{mol} \mathrm{hr}^{-1}$. On the other hand, $\mathrm{PO}_{4}{ }^{3-}$ excretion rate of major aquatic insects, Ephemeroptera (Heptageniidae), Diptera (Chironomidae), Plecoptera (Perlidae) and Odonata (Gomphidae) were 0.002 $\pm 0.001,0.0008 \pm 0.0002$, $0.005 \pm 0.002$, and $0.001 \pm 0.001 \mu \mathrm{mol} \mathrm{hr}{ }^{-1}$ respectively. $\mathrm{PO}_{4}{ }^{3-}$ excretion rate by Paratya compressa shrimp was $0.012 \pm 0.003 \mu \mathrm{mol} \mathrm{hr}^{-1}$.

Mass specific $\mathrm{NH}_{4}{ }^{+}$excretion rate of major aquatic insects, Ephemeroptera (Heptageniidae), Diptera (Chironomidae), Plecoptera (Perlidae), and Odonata (Gomphidae) were 23.96 \pm 7.19, $22.48 \pm 10.15,2.11 \pm$ 0.68 , and $15.35 \pm 3.98 \mu \mathrm{mol} \mathrm{hr}{ }^{-1} \mathrm{~g}^{-1}$ respectively. Mass specific $\mathrm{NH}_{4}{ }^{+}$excretion rate by Paratya compressa shrimp was $10.24 \pm 1.66 \mu \mathrm{mol} \mathrm{hr}^{-1} \mathrm{~g}^{-1}$, and in the range of variation among aquatic insects. On the other hand, mass-specific $\mathrm{PO}_{4}{ }^{3-}$ excretion rate of major aquatic insects, Ephemeroptera (Heptageniidae), Diptera (Chironomidae), Plecoptera (Perlidae), and Odonata (Gomphidae) were $4.55 \pm$ $3.19,9.82 \pm 7.28,0.67 \pm 0.21$, and $0.17 \pm 0.25 \mu \mathrm{mol} \mathrm{hr}^{-1} \mathrm{~g}^{-1}$ respectively. Mass specific $\mathrm{PO}_{4}{ }^{3-}$ excretion rate by Paratya compressa shrimp was $0.11 \pm 0.04 \mu \mathrm{mol} \mathrm{hr}^{-1} \mathrm{~g}^{-1}$, and lower compared to aquatic insects (Table 1B).

The calculated dry weight of shrimp was $1867 \mathrm{mg} \mathrm{m}^{-2}$. On the other hand, aquatic insect biomass was $909 \mathrm{mg} \mathrm{m}^{-2}$ in the absence of shrimps, and $823 \mathrm{mg} \mathrm{m}^{-2}$ in the presence of shrimps. Therefore, the total macroinvertebrate biomass was elevated were elevated from $909 \mathrm{mg} \mathrm{m}^{-2}$ to $2690 \mathrm{mg} \mathrm{m}^{-2}$ and about three times as high in the presence of shrimps (Fig. 3A). The calculated total $\mathrm{NH}_{4}{ }^{+}$excretion rate by shrimps was $14.4 \mu \mathrm{mol} \mathrm{hr}{ }^{-1} \mathrm{~m}^{-2}$. While total $\mathrm{NH}_{4}{ }^{+}$excretion by benthic macroinvertebrates except shrimps was slightly decreased when shrimps were present $\left(9.7 \mu \mathrm{mol} \mathrm{hr}^{-1} \mathrm{~m}^{-2}\right)$ compared to when shrimps were absent $\left(9.9 \mu \mathrm{mol} \mathrm{hr}{ }^{-1} \mathrm{~m}^{-2}\right)$, the total $\mathrm{NH}_{4}{ }^{+}$excretion rate by benthic macroinvertebrates including shrimps were elevated from $9.9 \mu \mathrm{mol} \mathrm{hr}^{1} \mathrm{~m}^{-2}$ to $24.2 \mu \mathrm{mol} \mathrm{hr} \mathrm{m}^{-1}$ and about 2.4 times as high in the presence of shrimps (Fig. 3B). The calculated total $\mathrm{PO}_{4}{ }^{3-}$ excretion rate by shrimps were 0.18 $\mu \mathrm{mol} \mathrm{hr}^{-1} \mathrm{~m}^{-2}$. While total $\mathrm{PO}_{4}{ }^{3-}$ excretion by benthic macroinvertebrates except shrimps was slightly decreased when shrimps were present $\left(1.28 \mu \mathrm{mol} \mathrm{hr}^{-1} \mathrm{~m}^{-2}\right)$ compared to when shrimps were absent $\left(1.40 \mu \mathrm{mol} \mathrm{hr}{ }^{-1} \mathrm{~m}^{-2}\right)$, the total $\mathrm{NH}_{4}{ }^{+}$excretion rate by benthic macroinvertebrates in absence of shrimp 
$1.40 \mu \mathrm{mol} \mathrm{hr}{ }^{-1} \mathrm{~m}^{-2}$ was almost the same as the total $\mathrm{NH}_{4}{ }^{+}$excretion in presence of shrimps $1.45 \mu \mathrm{mol}$ $\mathrm{hr}^{-1} \mathrm{~m}^{-2}$ (Fig. 3C).

\section{Field survey}

Amphidromous shrimp, Paratya compressa, Caridina multidentate, Palaemon paucidens, and Macrobrachium Formosense were observed in the study. Many shrimps occurred at night time, and less than $5 \%$ of shrimps were observed in day time, indicating they are nocturnal. Shrimps were observed at all the sites without dams, but no shrimps were observed upstream of dams. Model selections to explain the nutrient concentrations showed not only the physical characters such as drainage area of the watershed but also shrimp density can influence the water chemistry (Fig. 4,5, Table S4). Among nutrients analyzed in this study, $\mathrm{NH}_{4}{ }^{+}$concentration was not significantly influenced by shrimp density (Fig. 4A, $5 \mathrm{~A}$ ), while $\mathrm{NO}_{3}{ }^{-}$concentration significantly increased with shrimp density (Fig. $4 \mathrm{~B}, 5 \mathrm{~B}$ ). $\mathrm{PO}_{4}{ }^{3-}$ concentration was significantly decreased with shrimp density, and also decreased with drainage area and elevation (Fig. 4C, 5C). Chlorophyll-a density as well as the total aquatic insect biomass increased with drainage area (Fig. 4D, 5D), while the trend of aquatic insect biomass was not statistically significant (Fig. 4E, 5E). Among all aquatic insects, Heptageniidae, Chironomidae, Baetidae, Perlidae, and Leptophlebiidae were the five most abundant taxa. Their densities were strongly influenced by the drainage area, and the density of Heptageniidae and Perlidae were significantly higher and the density of Leptophlebiidae was significantly lower with increased drainage area (Fig. 4F, I, J, 5F, I, J). Perlidae density was significantly higher with increased elevation (Fig. 4I, 5I). Generally, the densities of the five dominant aquatic insects were lower with increased density of shrimps but that was not statistically significant (Fig. 4F-J, 5F-J).

\section{Discussion}

The present study shows that the density of amphidromous shrimps not only influence stream biota through species interactions but also influence stream nutrient cycling through their excretion. While the direct evaluation of the animal excretion on stream nutrient cycling in stream is challenging due to the flow, by a combination of the field manipulative experiment and field survey, we showed the mechanisms as well as the natural variation of nutrient concentrations that amphidromous shrimps induced. This study represents one of the limited studies that carefully evaluated both the biological and chemical influence of process subsidies (Flecker et al. 2010), and the results indicate the potentially large impacts of the underappreciated amphidromous organisms on the stream ecosystem.

The presence of shrimps as strong competitors slightly decreased the biomass of aquatic insects but increased the total biomass of benthic macroinvertebrates in the field manipulative experiment. This result meets the theory by Tilman et al. (1997), which predicts the increase in total biomass of assemblages when a more efficient species is added. The reduction in BFPOM indicate shrimps were more effective consumer of BFPOM (Pringle \& Blake 1994) than other aquatic insects such as 
Chironomidae, which are also known as detritus feeder (Merritt et al. 2019). It is assumed that shrimp outcompeted aquatic insects such as Chironomidae that share the resource, and more effectively utilized the resource as the whole benthic macroinvertebrate assemblage. Furthermore, increased Chlorophyll-a density in the presence of shrimps in the experiment probably occurred due to the removal of BFPOM by shrimps that cover and shade periphyton in streams (Power 1990; Kupferberg 1997). The increased primary production of periphyton by the removal of BFPOM would explain the biomass compensation of periphyton feeders such as Baetidae (Merritt et al. 2019) in the presence of shrimps. In addition, the longer lifespan of the shrimps (> 2 years; Kawai \& Kazuyoshi 2011) compared to the competing aquatic insect species such as Chironomidae (a few months to one year; Kawai \& Tanida 2018) contributed to the high biomass of shrimps in contrast to the little reduction of aquatic insect biomass, and increased the total benthic macroinvertebrate biomass.

Excretion measurement of the major aquatic insect taxa and shrimp and the estimation of the total excretion rate by the benthic macroinvertebrate assemblages in the presence/absence of shrimps showed chemical influence of shrimps. The mass-specific $\mathrm{NH}_{4}{ }^{+}$excretion of shrimp was in the range of variation among aquatic insects as previously documented (Vanni et al. 2017), and increased total biomass of the benthic macroinvertebrates increased total $\mathrm{NH}_{4}{ }^{+}$excretion in presence of shrimps. The total $\mathrm{NH}_{4}{ }^{+}$excretion by benthos was $24.2 \mu \mathrm{mol} \mathrm{m}{ }^{-2} \mathrm{~h}^{-1}$ in the presence of shrimps, and that was 2.4 times as much as their absence. The contribution of these nutrient excretions by the benthic macroinvertebrates to the ecosystem-level nutrient cycling is not directly evaluated in this study, as it also depends on nutrient uptake rates that were not measured in this study. However, Benstead et al. (2010) have estimated that the same level of nutrient excretion by shrimps $\left(22.3 \mu \mathrm{mol} \mathrm{NH_{4 }}{ }^{+}\right)$represented $21 \%$ of $\mathrm{NH}_{4}{ }^{+}$ uptake in a tropical stream. Therefore, it is assumed that the elevated $\mathrm{NH}_{4}{ }^{+}$excretion by the benthic macroinvertebrates in the presence of shrimps observed in this study also contributed to the whole stream nitrogen cycling.

In the spatial survey, variation in the shrimp density was not reflected in $\mathrm{NH}_{4}{ }^{+}$concentration but reflected in $\mathrm{NO}_{3}{ }^{-}$concentration. $\mathrm{NO}_{3}{ }^{-}$concentration in streams with high shrimp density was on average twice as high as those without shrimp. While excretion of nitrogen from benthos was in the form of $\mathrm{NH}_{4}{ }^{+} \mathrm{N}$, it is assumed that $\mathrm{NH}_{4}{ }^{+}-\mathrm{N}$ from the benthic macroinvertebrate assemblages was nitrified to $\mathrm{NO}_{3}{ }^{-}{ }^{-}{ }^{-}$in streams. (Newbold et al. 1983; Day and Hall 2017). This is a contrast to most studies that measured an increase in nutrient level from fish excretion, which documented increased $\mathrm{NH}_{4}{ }^{+}$but not $\mathrm{NO}_{3}{ }^{-}$(Hall et al. 2003; McIntyre et al. 2008). We believe that the difference comes from the habitats of the shrimps and fishes that have been studied for excretion. Most excretion studies in stream ecosystems to date have been conducted with anadromous salmons or suckers that migrate from the ocean or lakes to downstream reaches of streams for spawning. Therefore, there were not long enough distances downstream of spawning ground for nitrification. In contrast, amphidromous shrimps we studied migrate up to headwater areas of streams, and the stream water continuously receives shrimp excretion from headwater to the sampling sites over long distances. Furthermore, habitat of the shrimps, the benthic 
zone of headwater streams, is where nitrification occurs most actively in streams (Ensign and Doyle 2006; Hall et al. 2013). When $\mathrm{NH}_{4}{ }^{+}$concentration is elevated, nitrification should occur actively in biofilms in oxic sediments in mountainous streams like where this study was conducted (Butturini et al. 1999). Reduction of BFPOM as a result of shrimp activity as observed in the electroshock experiment may have also contributed to activate the nitrification by oxidizing the sediment (Stief 2013).

In contrast, shrimp excreted much less $\mathrm{PO}_{4}{ }^{3-}$ compared to aquatic insects, and the total $\mathrm{PO}_{4}{ }^{3-}$ excretion by benthic macroinvertebrate assemblages were similar regardless of the presence of shrimps. As crustaceans require a large amount of phosphorous for their carapace (Vrede et al. 1999), crustaceans generally excrete low $\mathrm{PO}_{4}{ }^{3-}$ compared to other aquatic consumers such as aquatic insects and snails (Evans-White et al. 2005; McManamay et al. 2011). Therefore, the dominance of shrimps in benthic macroinvertebrate assemblages would decrease the phosphorous excretion by the benthic macroinvertebrate assemblages. In this study, total $\mathrm{PO}_{4}{ }^{3-}$ excretion by benthic macroinvertebrate assemblages were similar in the presence/absence of shrimps, because the reduction in aquatic insect density was limited. However, the strength of species interaction is condition-dependent (Menge et al. 2004), and slightly stronger dominance of shrimps and stronger suppression of aquatic insects compared to this study, which would lead to the reduction of total phosphorous excretion by the benthic macroinvertebrates, could occur under different conditions. The result of the spatial survey showed a negative correlation of shrimp density on $\mathrm{PO}_{4}{ }^{3-}$ concentration in stream water, while $\mathrm{PO}_{4}{ }^{3-}$ concentration had a stronger negative correlation with the drainage area and the elevation of the sampling site. Lower $\mathrm{PO}_{4}{ }^{3-}$ concentration in high elevation indicates that the phosphorous export from the drainage area is lower due to the low weathering rate of the bedrock (Hartmann et. al. 2011; Lintern et al. 2018). Lower $\mathrm{PO}_{4}{ }^{3-}$ concentration with increased drainage area is explained by more active photosynthesis by algae downstream (Finlay et al. 2011). In addition, the dominance of shrimps that excrete little phosphorous could have resulted in the reduction in the $\mathrm{PO}_{4}{ }^{3-}$ concentration in stream water.

Nutrient in stream water is often considered as output from the terrestrial ecosystems (Brookshire et al. 2009), and the variation in the nutrient level is attributed to environmental condition of the watershed including geology (Holloway et al. 1998) and forest type or age (Likens et al. 1970; Wakamatsu et al. 2006). The result of this study shows that not only the upstream watershed conditions but also the downstream connectivity to the ocean can also influence the nutrient in stream water through the excretion of migratory organisms. It is particularly surprising in such mountainous headwater streams far from the ocean as studied in this research. Greathouse et al. (2006) has shown upstream effects of dams by extirpation of amphidromous organisms. Though they only found the reduction in aquatic insects through species interactions, the result of this study shows the upstream effect of the dams can be extended to nutrient cycling.

Loss of habitat connectivity often leads to the decline in animal diversity (Fahrig et al. 2003; Cardinale et al. 2012). The result of this study shows the loss of a migratory species can lead to change not only in community structures but also in nutrient cycling. While the ecological consequences of the loss in large 
animals and/or animals with commercial importance have gathered much attention (Lichatowich et al. 2001), ecological consequences of the loss in such small and invisible organisms like shrimps are often dismissed. This study urges us to study the ecological functions of various consumers.

\section{Declarations}

\section{Acknowledgments}

We thank the Seto Marine Biological Laboratory of the Field Science Education and Research Center, Kyoto University for their field assistance, logistic supports, and accommodation. We also thank Wakayama Experimental Forest, Hokkaido University for field access and accommodation. Mizushi Yokoi, Naoki Yui, Kseniya Lyalina, Ryosuke Tanaka, and Yusuke Fuke are acknowledged for their field assistance. This study was financially supported by the Sasakawa Scientific Research Grant from the Japan Science Society as well as the Japan River Front Research Center and the Ministry of Land, Infrastructure, Transport, and Tourism.

\section{Declarations}

Conflict of Interest: The authors declare that they have no conflict of interest.

Ethics approval: All applicable institutional and/or national guidelines for the care and use of animals were followed.

Availability of data and materials: The datasets used and/or analysed during the current study are available from the corresponding author on reasonable request.

\section{References}

1. Benstead, J. P., Cross, W. F., March, J. G., McDowell, W. H., Ramirez, A., \& Covich, A. P. (2010). Biotic and abiotic controls on the ecosystem significance of consumer excretion in two contrasting tropical streams. Freshwater Biology, 55 (10), 2047-2061. 2. Brookshire, E. N. J., Valett, H. M., \& Gerber, S. (2009).

Maintenance of terrestrial nutrient loss signatures during in-stream transport. Ecology, 90 (2), 293-299. 3. Burnham, K. P., \& Anderson, D. R. (2002). Model selection and multimodel inference, 2nd edn New York. NY: Springer. 4. Butturini, A., Battin, T. J., \& Sabater, F. (2000). Nitrification in stream sediment biofilms: the role of ammonium concentration and DOC quality. Water Research, 34 (2), 629-639. 5. Cardinale, B. J., Duffy, J. E., Gonzalez, A., Hooper, D. U., Perrings, C., Venail, P., ... \& Naeem, S. (2012). Biodiversity loss and its impact on humanity. Nature, 486 (7401), 59-67. 6. Carpenter, S. R., Kitchell, J. F., \& Hodgson, J. R. (1985). Cascading trophic interactions and lake productivity. BioScience, 35 (10), 634-639. 7. Childress, E. S., \& Mclntyre, P. B. (2015). Multiple nutrient subsidy pathways from a spawning migration of iteroparous fish. Freshwater Biology, 60 (3), 490-499. 8. Covich, A. P. (1988). Geographical and historical comparisons of neotropical streams: biotic diversity and detrital processing in highly variable habitats. Journal of the North American Benthological Society, 7 (4), 361-386. 9. Cross, W. F., Covich, A. P., Crowl, T. A., Benstead, 
J. P., \& Ramirez, A. (2008). Secondary production, longevity and resource consumption rates of freshwater shrimps in two tropical streams with contrasting geomorphology and food web structure. Freshwater Biology, 53 (12), 2504-2519. 10. Day, N. K., \& Hall Jr, R. O. (2017). Ammonium uptake kinetics and nitrification in mountain streams. Freshwater Science, 36 (1), 41-54. 11. Ensign, S. H., \& Doyle, M. W. (2006). Nutrient spiraling in streams and river networks. Journal of Geophysical Research:

Biogeosciences, 111 (G4). 12. Evans-White, M. A., \& Lamberti, G. A. (2005). Grazer species effects on epilithon nutrient composition. Freshwater Biology, 50 (11), 1853-1863. 13. Fahrig, L. (2003). Effects of habitat fragmentation on biodiversity. Annual review of ecology, evolution, and systematics, 34 (1), 487515. 14. Finlay, J. C., Hood, J. M., Limm, M. P., Power, M. E., Schade, J. D., \& Welter, J. R. (2011). Lightmediated thresholds in stream-water nutrient composition in a river network. Ecology, 92 (1), 140-150. 15. Flecker, A. S., McIntyre, P. B., Moore, J. W., Anderson, J. T., Taylor, B. W., \& Hall Jr, R. O. (2010). Migratory fishes as material and process subsidies in riverine ecosystems. In American Fisheries Society Symposium, 73 (2), 559-592. 16. Gende, S. M., Edwards, R. T., Willson, M. F., \& Wipfli, M. S. (2002). Pacific salmon in aquatic and terrestrial ecosystems: Pacific salmon subsidize freshwater and terrestrial ecosystems through several pathways, which generates unique management and conservation issues but also provides valuable research opportunities. BioScience, 52 (10), 917-928. 17. Greathouse, E. A., Pringle, C. M., McDowell, W. H., \& Holmquist, J. G. (2006). Indirect upstream effects of dams: consequences of migratory consumer extirpation in Puerto Rico. Ecological Applications, 16 (1), 339-352. 18. Guha-Sapir, D., Hargitt, D., \& Hoyois, P. (2004). Thirty years of natural disasters 1974-2003: The numbers. Presses univ. de Louvain. 19. Hall Jr, R. O., Tank, J. L., \& Dybdahl, M. F. (2003). Exotic snails dominate nitrogen and carbon cycling in a highly productive stream. Frontiers in Ecology and the Environment, 1 (8), 407-411. 20. Hall Jr, R. O., Baker, M. A., Rosi-Marshall, E. J., Tank, J. L., \& Newbold, J. D. (2013). Solute-specific scaling of inorganic nitrogen and phosphorus uptake in streams. Biogeosciences, 10 (11), 7323-7331. 21. Hanski, I., \& Kuussaari, M. (1995). Butterfly metapopulation dynamics. Population dynamics: new approaches and synthesis, 8, 149-171. 22. Hartmann, J., \& Moosdorf, N. (2011). Chemical weathering rates of silicate-dominated lithological classes and associated liberation rates of phosphorus on the Japanese Archipelago-Implications for global scale analysis. Chemical Geology, 287 (3-4), 125157. 23. Holloway, J. M., Dahlgren, R. A., Hansen, B., \& Casey, W. H. (1998). Contribution of bedrock nitrogen to high nitrate concentrations in stream water. Nature, 395 (6704), 785-788. 24. Kawai, T., Kazuyoshi, N. (2011) Shrimps, Crabs, and Crayfishes [published in Japanese], Seibutsukenkyusya. 25. Kawai, T, Tanida, K. (2018) Aquatic insects in Japan [published in Japanese] Tokai-publisher 26. Kitchell, J. F., O'Neill, R. V., Webb, D., Gallepp, G. W., Bartell, S. M., Koonce, J. F., \& Ausmus, B. S. (1979). Consumer regulation of nutrient cycling. BioScience, 29(1), 28-34. 27. Kupferberg, S. (1997). Facilitation of periphyton production by tadpole grazing: functional differences between species. Freshwater Biology, 37(2), 427-439. 28. Lichatowich, J., \& Lichatowich, J. A. (2001). Salmon without rivers: a history of the Pacific salmon crisis. Island Press. 29. Likens, G. E., Bormann, F. H., Johnson, N. M., Fisher, D. W., \& Pierce, R. S. (1970). Effects of forest cutting and herbicide treatment on nutrient budgets in the Hubbard Brook watershed-ecosystem. Ecological monographs, 40 (1), 23-47. 30. Lintern, A., Webb, J. A., Ryu, D., Liu, S., Waters, D., Leahy, P., ... \& Western, A. W. (2018). What are the key catchment characteristics affecting spatial differences in riverine water quality?. Water Resources Research, 54 (10), 7252-7272. 31. Mantel, 
S. K., \& Dudgeon, D. (2004). Growth and production of a tropical predatory shrimp, Macrobrachium hainanense (Palaemonidae), in two Hong Kong streams. Freshwater Biology, 49 (10), 1320-1336. 32. McManamay, R. A., Webster, J. R., Valett, H. M., \& Dolloff, C. A. (2011). Does diet influence consumer nutrient cycling? Macroinvertebrate and fish excretion in streams. Journal of the North American Benthological Society, 30 (1), 84-102. 33. McDowall, R. M. (1988). Diadromy in fishes: migrations between freshwater and marine environments. Croom Helm. 34. McIntyre, P. B., Jones, L. E., Flecker, A. S., \& Vanni, M. J. (2007). Fish extinctions alter nutrient recycling in tropical freshwaters. Proceedings of the National Academy of Sciences, 104 (11), 4461-4466. 35. McIntyre, P. B., Flecker, A. S., Vanni, M. J., Hood, J. M., Taylor, B. W., \& Thomas, S. A. (2008). Fish distributions and nutrient cycling in streams: can fish create biogeochemical hotspots. Ecology, 89 (8), 2335-2346. 36. Menge, B. A., Blanchette, C., Raimondi, P., Freidenburg, T., Gaines, S., Lubchenco, J., ... \& Pamplin, J. (2004). Species interaction strength: testing model predictions along an upwelling gradient. Ecological Monographs, 74 (4), 663-684. 37. Merritt, R., Cummins, K. \& Berg. M.B. (2019) An introduction to the aquatic insects of North America, 5th edition. Kendall Hunt Pub Co. 38. Moerke, A. H., Ruetz, C. R. Simon T. N., Pringle, C. M. (2017) MacroconsumerResource Interactions. Methods in stream ecology: Volume 1: Ecosystem structure. Academic Press. Hauer, F. R., \& Lamberti, G. (Eds.). 39. Myers, G. S. (1949). Usage of anadromous, catadromous and allied terms for migratory fishes. Copeia, 1949 (2), 89-97. 40. Nagasawa, K., Sato, T., \& Sasagawa, K. (2020). A giant mottled eel, Anguilla marmorata Quoy and Gaimard, 1824 (Anguilliformes: Anguillidae), from a small urban river in Shizuoka Prefecture, central Japan [published in Japanese]. Nature of Kagoshima: an annual magazine for naturalists, 46, 367-370. 41. Newbold, J. D., Elwood, J. W., Schulze, M. S., Stark, R. W., \& Barmeier, J. C. (1983). Continuous ammonium enrichment of a woodland stream: uptake kinetics, leaf decomposition, and nitrification. Freshwater Biology, 13, 193-204. 42. Paine, R. T. (1980). Food webs: linkage, interaction strength and community infrastructure. Journal of animal ecology, 49 (3), 667-685. 43. Power, M. E. (1990). Resource enhancement by indirect effects of grazers: armored catfish, algae, and sediment. Ecology, 71 (3), 897-904. 44. Pringle, C. M., Blake, G. A., Covich, A. P., Buzby, K. M., \& Finley, A. (1993). Effects of omnivorous shrimp in a montane tropical stream: sediment removal, disturbance of sessile invertebrates and enhancement of understory algal biomass. Oecologia, 93(1), 1-11. 45. Pringle, C. M., \& Blake, G. A. (1994). Quantitative effects of atyid shrimp (Decapoda: Atyidae) on the depositional environment in a tropical stream: use of electricity for experimental exclusion. Canadian Journal of Fisheries and Aquatic Sciences, 51 (6), 1443-1450. 46. Saito, M., Yamashiro, T., Hamano, T., \& Nakata, K. (2012). Factors affecting distribution of freshwater shrimps and prawns in the Hiwasa River, southern central Japan. Crustacean research, 41, 27-46. 47. Scheibling, R. (1986). Increased macroalgal abundance following mass mortalities of sea urchins (Strongylocentrotus droebachiensis) along the Atlantic coast of Nova Scotia. Oecologia, 68 (2), 186-198. 48. Stief, P. (2013). Stimulation of microbial nitrogen cycling in aquatic ecosystems by benthic macrofauna: mechanisms and environmental implications. Biogeosciences, 10 (12), 7829-7846. 49. Suzuki, R., \& Ishimaru, T. (1990). An improved method for the determination of phytoplankton chlorophyll using $\mathrm{N}, \mathrm{N}$-dimethylformamide. Journal of the Oceanographical Society of Japan, 46 (4), 190-194. 50. Tokuoka, T., Harata, T., Suzuki, H. \& Yao, A. (1981) 1:200,000 Geology map "Tanabe" [published in Japanese], Geology Survey of Japan: https://www.gsj.jp/data/200KGM/JPG/GSJ_MAP_G200_NI5316_1982_200dpi.jpg 51. Tanaka, R., 
Hirashima, K., Kunishima, T., Uno, H., \& Sato, T. (2020). Phenological diversity of freshwater migration can prolong assemblage-level migration period in amphidromous fishes in a temperate river system in Japan. Ecological Research, 35 (3), 494-503. 52. Taylor, B. W., Flecker, A. S., \& Hall, R. O. (2006). Loss of a harvested fish species disrupts carbon flow in a diverse tropical river. Science, 313 (5788), 833-836. 53. Tilman, D. (1977). Resource competition between plankton algae: an experimental and theoretical approach. Ecology, 58 (2), 338-348. 54. Vanni, M. J. (2002). Nutrient cycling by animals in freshwater ecosystems. Annual Review of Ecology and Systematics, 33 (1), 341-370. 55. Vanni, M. J., \& Layne, C. D. (1997). Nutrient recycling and herbivory as mechanisms in the "top-down" effect of fish on algae in lakes. Ecology, 78 (1), 21-40. 56. Vanni, M., Mclntyre, P., Allen, D., Arnott, D., Benestad, J., Berg, D., ... \& Zimmer, K. D. (2017). A global database of nitrogen and phosphorous excretion rates of aquatic animals. Ecology, 98,1475. 57. Vrede, T., Andersen, T., \& Hessen, D. O. (1999). Phosphorus distribution in three crustacean zooplankton species. Limnology and Oceanography, 44 (1), 225-229. 58. Wakamatsu, T., Konohira, E., Shindo, J., Yoshioka, T., Okamoto, K., Itaya, A. \& Kim, M. (2006) Dissolved inorganic phosphate concentration in stream water in Japan and factors controlling the concentration [published in Japanese]. Journal of Japan Society on Water Environment, 22 (11) 679-686. 59. Zuur, A. F., leno, E. N., \& Elphick, C. S. (2010). A protocol for data exploration to avoid common statistical problems. Methods in ecology and evolution, 1 (1), 3-14.

\section{Table}

Due to technical limitations, table 1 is only available as a download in the supplementary files section.

\section{Figures}




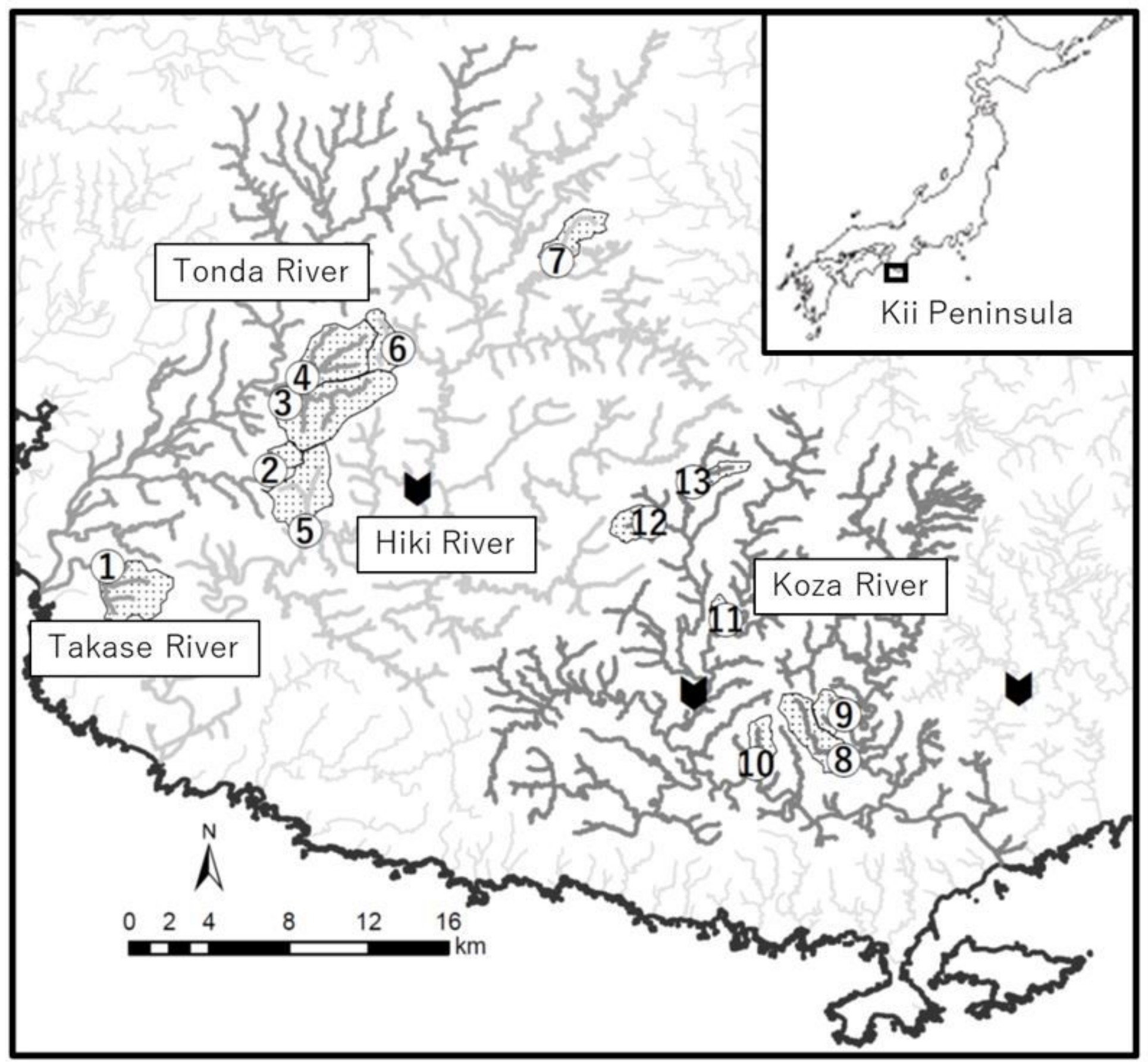

Figure 1

Points in the map indicate surveyed sites in this study. All sites were located in distinct tributaries of the Tonda River, the Takase River, the Hiki River, and the Koza River in Wakayama, Japan. The field manipulative experiment and the measurement of the consumer excretion were conducted at site 1 in the Takase River. 

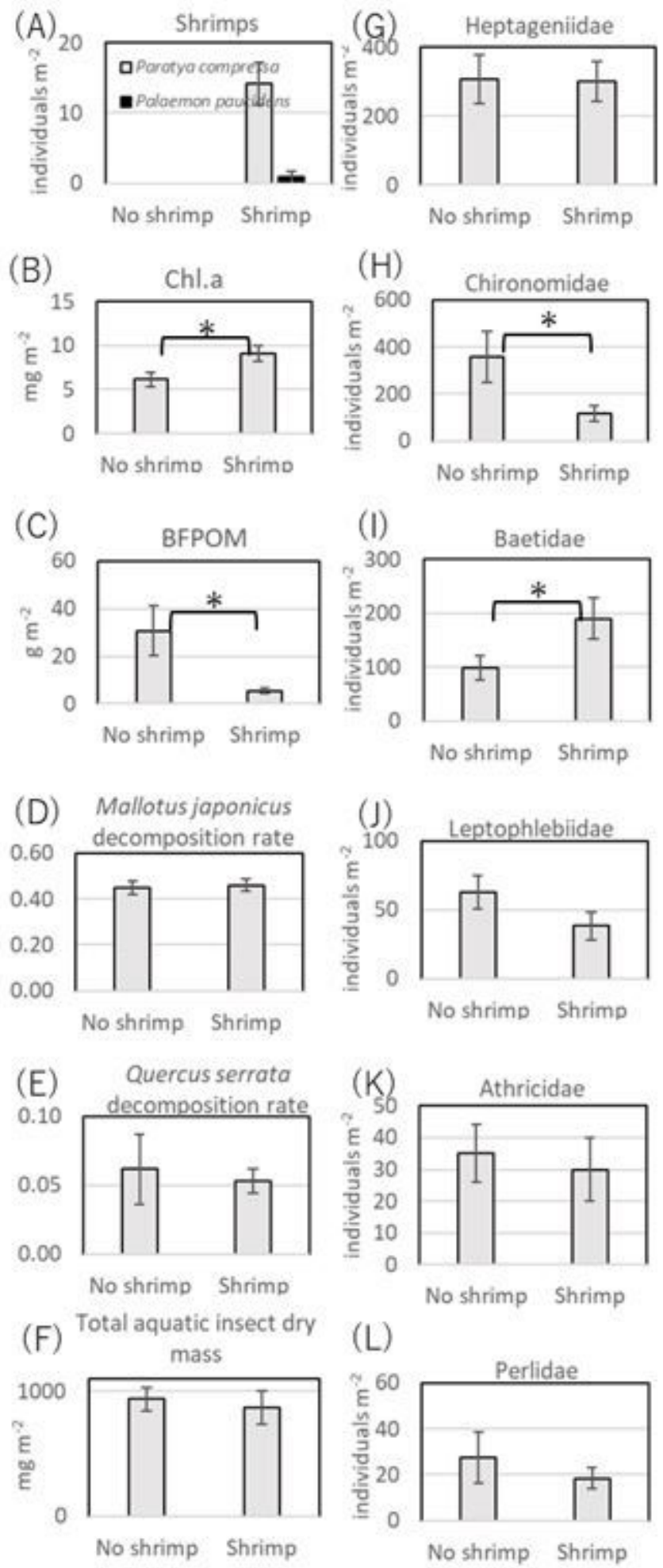

Figure 2

Shrimp density (A), Chlorophyll-a density (B), fine benthic particulate organic matter (BFPOM) density (C), and decomposition rate of two dominant riparian tree leaves $(D, E)$, total aquatic insect dry mass $(F)$, as well as the density of the six most abundant benthic aquatic insect families in the survey $(G-L)$. 

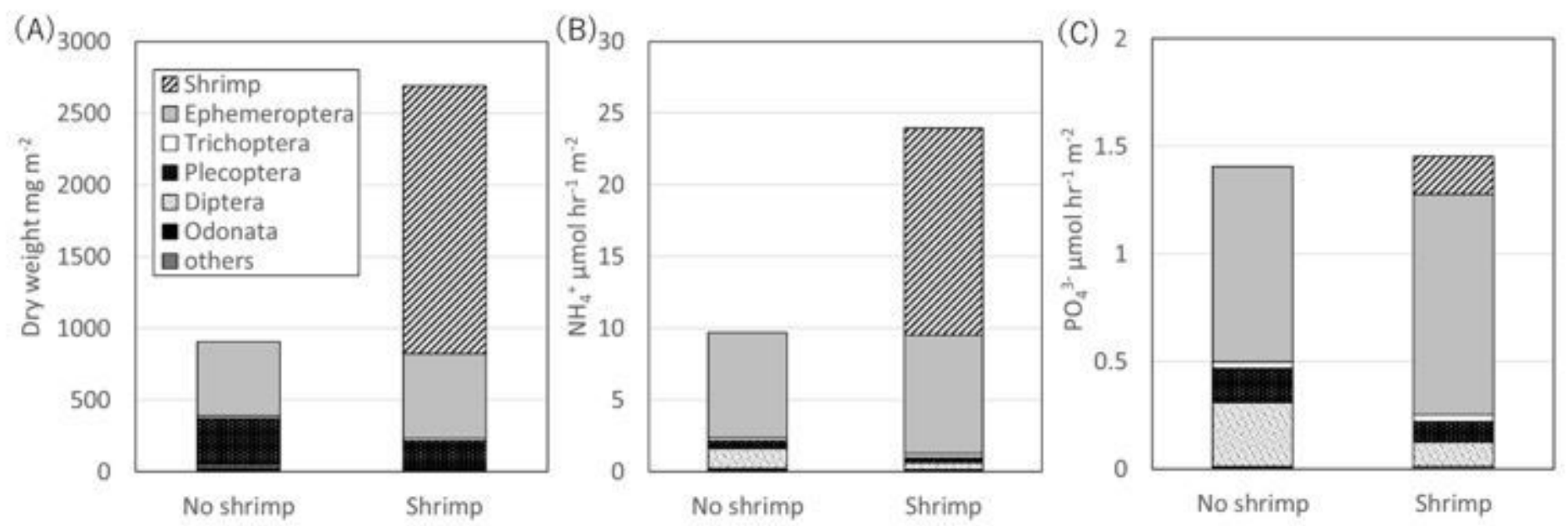

Figure 3

Calculated mean dry weight (A), $\mathrm{NH} 4+$ excretion rate (B), and P043- excretion rate (C) of benthic macroinvertebrate assemblages from the experimental chambers with electroshock (no shrimp) and without electroshock (with shrimp). 
(A)

Forest rate $(0.44)$

Drainage area $(0.40)$

Natural forest $(0.21)$

Shrimp density $(0.18)$

Elevation (0.15)

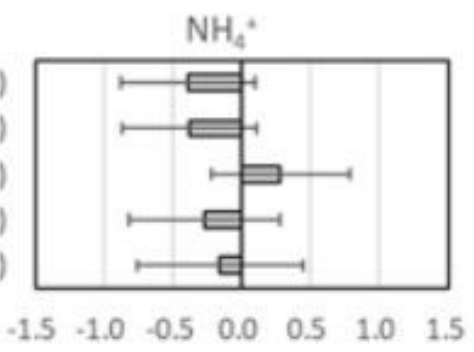

(B)

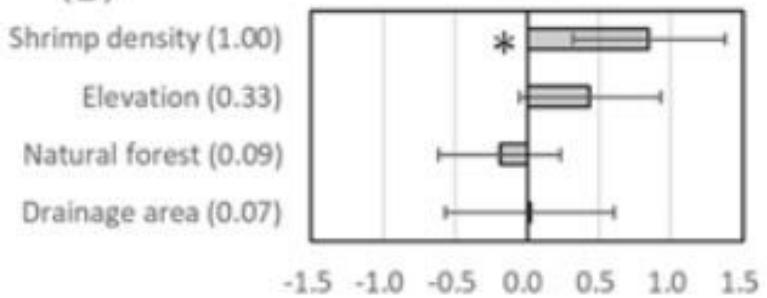

(C)

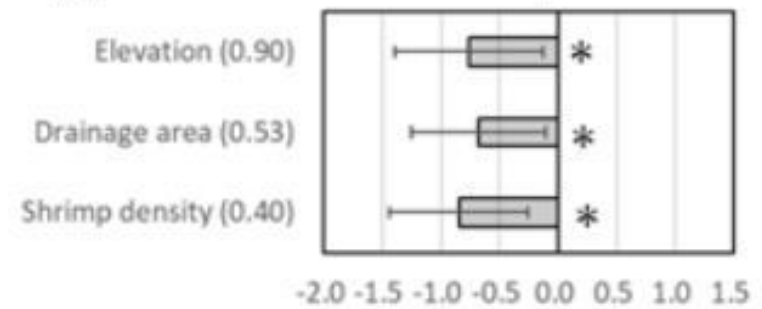

(D)

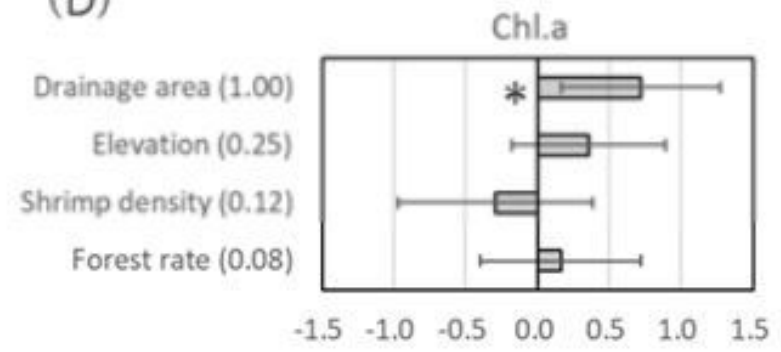

(E)

Total aquatic insect dry mass

Drainage area (0.57)

Natural forest (0.19)

Shrimp density (0.18)

Elevation (0.18)

Forest rate $(0.14)$

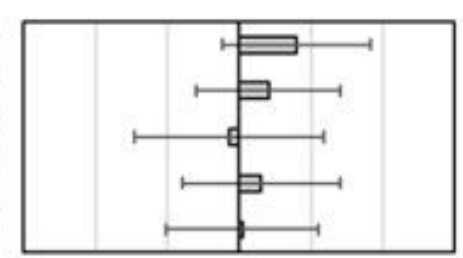

$\begin{array}{lllllll}-1.5 & -1.0 & -0.5 & 0.0 & 0.5 & 1.0 & 1.5\end{array}$
(F) Heptageniidae

Drainage area (0.92)

Shrimp density (0.18)

Natural forest $(0.16)$

Elevation $(0.09)$

Forest rate $(0.07)$

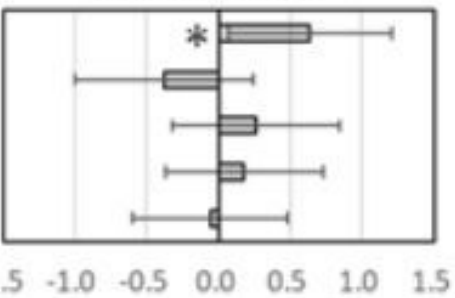

(G)

Elevation $(0.47)$

Forest rate (0.24)

Shrimp density $(0.18)$

Natural forest $(0.17)$

Drainage area $(0.15)$

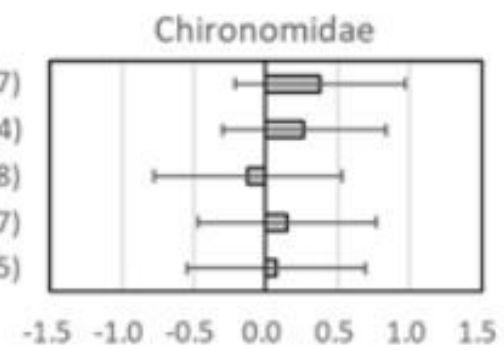

(H)

Shrimp density $(0.40)$

Forest rate $(0.25)$

Drainage area $(0.25)$

Elevation (0.24)

Natural forest $(0.14)$

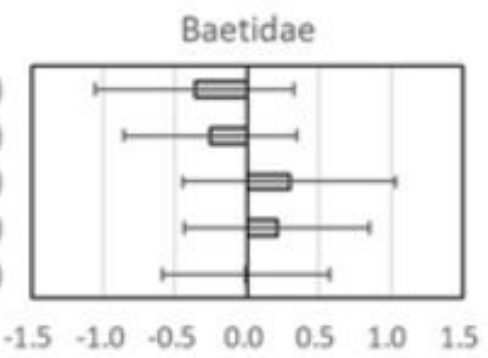

(

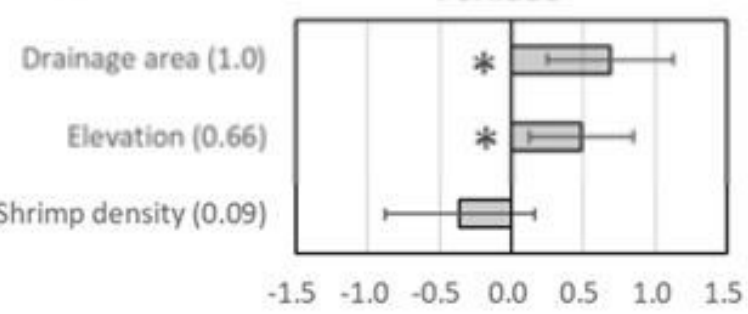

( $)$

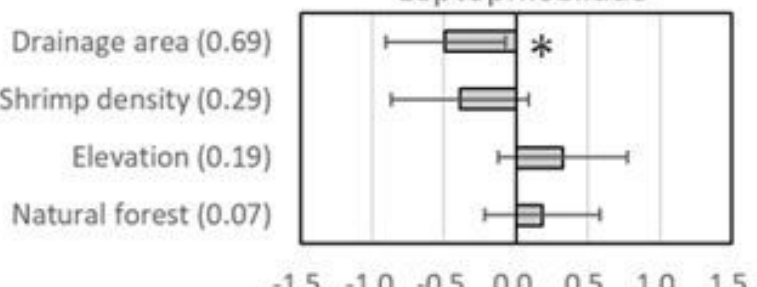

\section{Figure 4}

Standardized coefficients for nutrient concentration (A-C), Chlorophyll-a (D), total aquatic insect dry mass (E), and density of major aquatic insect taxa (F-J). Each predictor is retained in the final confidence model set with $\triangle \mathrm{AICc} \varangle 4$. The values following each predictor name are the relative variable importance (RVI), calculated as the sum of the model weights of all the models in the final confidence set in which the variable appears. The asterisk indicates where $95 \%$ confidence intervals do not cross zero. 

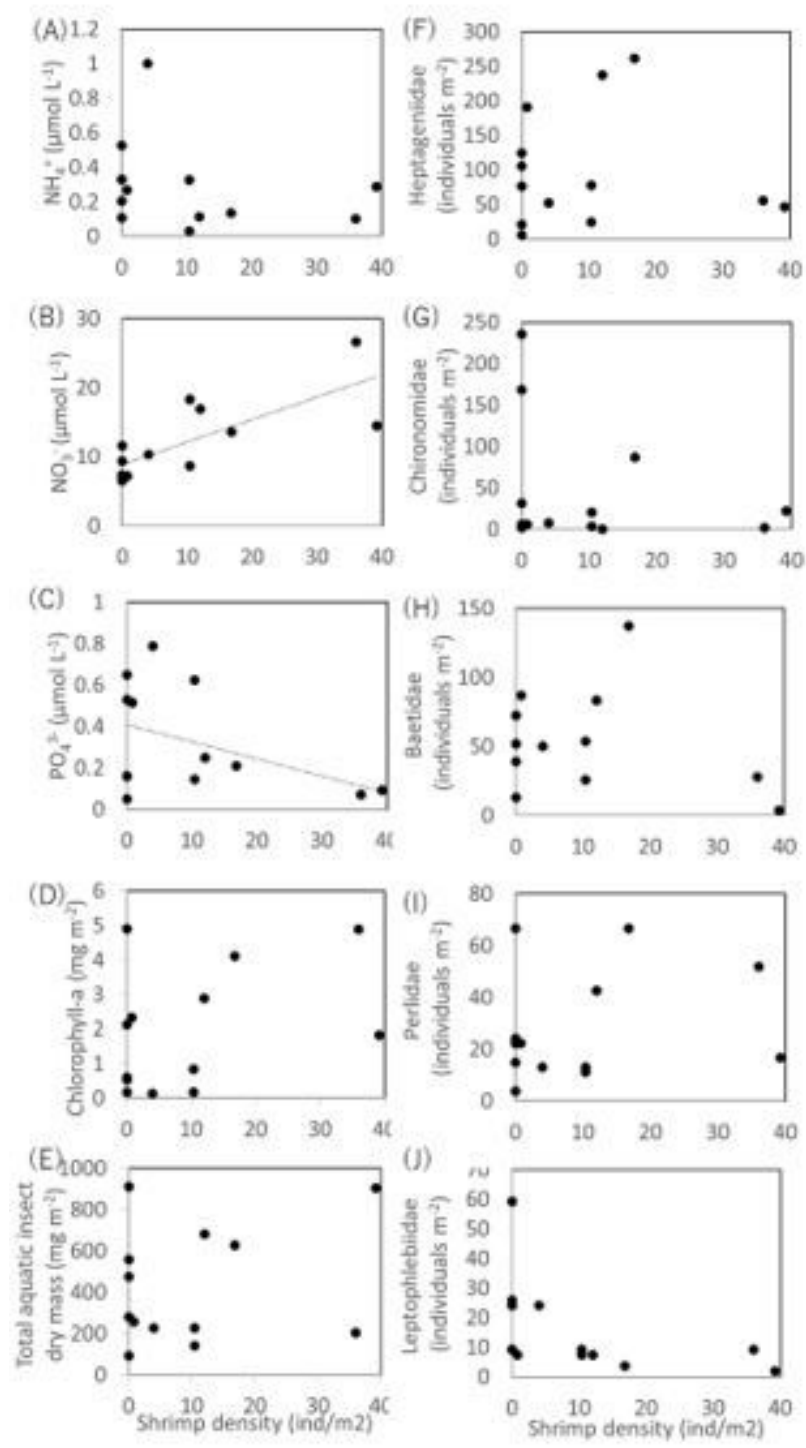

Figure 5

Relationship between the shrimp density and nutrient concentration (A-C), Chlorophyll-a (D), total aquatic insect dry mass $(E)$, and density of major aquatic insect taxa (F-J). Each dot represents a surveyed site.

\section{Supplementary Files}

This is a list of supplementary files associated with this preprint. Click to download.

- table.docx

- Supplimentaryfile.docx 